\title{
A ABORDAGEM DO GÊNERO EM DOIS LIVROS DIDÁTICOS DE LÍNGUA PORTUGUESA DESTINADOS AO ENSINO MÉDIO
}

\author{
THE APPROACH TO SPEECH GENRES IN TWO HIGH SCHOOL BOOKS AIMING \\ AT PORTUGUESE LANGUAGE TEACHING
}

\author{
Ana Paula Kuczmynda Silveira \\ Mestranda em Lingüística - UFSC - CNPq
}

\begin{abstract}
Resumo
Este artigo tem aporte na teoria dos gêneros do discurso, conforme sugerida por Bakhtin, e objetiva discutir a abordagem do gênero em dois livros de Língua Portuguesa recomendados pelo Programa Nacional do Livro Didático para o Ensino Médio PNLEM - para adoção, em todo o território nacional. Para tanto, partiu-se de uma reflexão sobre o papel do livro didático na mediação do ensino/aprendizagem e sobre a discussão teórico-metodológica proposta pelos documentos oficiais para o ensino médio a respeito da abordagem do gênero em práticas de leitura, escuta e produção textual. Análise dos livros didáticos concentrou-se na abordagem teórico-metodológica do gênero no manual do professor e nas atividades de leitura e produção textual. Percebeuse que a confusão terminológica que cerca a questão do gênero, envolvendo expressões como - tipo textual, seqüência textual, gênero textual - a despeito de diferenças conceituais entre eles, vê-se refletida na forma como o gênero é abordado nas atividades de leitura e produção do texto, as quais se centralizam mais em aspectos textuais do que em aspectos interacionais.
\end{abstract}

Palavras-chave: Livro didático. Leitura. Produção textual. Gênero do discurso.

\begin{abstract}
The present article is anchored in the theory of speech genres, as suggested by Bakhtin, and aims at discussing the way the genre is approached within two books of Portuguese Language recommended by The National Program for Didactic Books for High school - PNLEM - to be adopted, all over Brazil. The starting point to do that, was the development of a reflection about the didactic books` role in the mediation of the teaching/learning process and about the theoretical-methodological discussion, regarding the genre within reading, listening and writing practices, performed by the official documents for high school. The analysis of the didactic books focused on the theoretical-methodological approach to the genre in the teacher's manual and within reading and writing activities. It was noticed that the terminological confusion related to the genre, which involves terms as - textual type, textual sequence, textual genre regardless the conceptual differences among them, reflects on the way the genre is approached in the activities involving reading and writing, which give more importance to textual aspects than to interactional aspects.
\end{abstract}

Key-words: Didactic book. Reading. Writing. Speech genre. 


\section{INTRODUÇÃO}

Em 1998, atendendo ao anseio por mudanças nos rumos da educação brasileira e com o objetivo de fornecer aos educadores diretrizes para o ensino/aprendizagem das diversas disciplinas curriculares, surgiram os Parâmetros Curriculares Nacionais (PCN).

Em sua introdução, os PCN ressaltam a importância da seleção adequada de recursos didáticos para uso em sala de aula e apontam que “[...] o livro didático é um dos materiais de mais forte influência na prática de ensino brasileira.”, sendo necessário que os professores, ao selecionarem um livro ou grupo de livros didáticos para uso no contexto escolar, atentem "[...] à qualidade, à coerência e a eventuais restrições que [tais livros] apresentem em relação aos objetivos educacionais propostos.” (BRASIL, 1998, p.96).

Para oportunizar o acesso dos alunos aos livros didáticos em todo o território nacional, bem como sua distribuição e seleção criteriosa, o Ministério da Cultura (MEC) criou o Programa Nacional do Livro Didático (PNLD), visando, inicialmente, à distribuição dos livros didáticos selecionados nas séries do ensino fundamental, o que ocorreu, pela primeira vez, em 1997. Na esteira do PNLD, foi implantado, em 2004, o Programa do Livro Didático para o Ensino Médio - PNLEM (BRASIL, 2004).

A distribuição de livros didáticos aos alunos do ensino médio para a disciplina de Língua Portuguesa tornou-se uma prática em todo o território nacional em 2006, sendo recomendados doze títulos (BRASIL, 2006). Dentre esses, optamos por contemplar, no contexto dessa pesquisa, dois - Português: Linguagens, de William Roberto Cereja e Thereza A. C. Magalhães; e Português - Língua e Cultura, de Carlos Alberto Faraco. A escolha deveu-se ao fato de o primeiro constituir o livro didático mais adotado na rede pública de ensino, conforme estatística do próprio MEC, e de o segundo apresentar uma seleção, apresentação e abordagem metodológica diferenciada dos conteúdos contemplados pela disciplina de Língua Portuguesa (se comparado aos demais livros didáticos recomendados pelo MEC para o ensino médio), tendo ficado em quinto lugar entre os mais adotados em 2006 e em quarto lugar em 2008 (BASE, 2008). Ambos os livros são edições em volume único, destinadas às três séries do ensino médio e englobam os conteúdos de Língua Portuguesa e Literatura Brasileira.

A pesquisa centralizou-se na abordagem teórico-metodológica que os dois livros apresentam para as questões relacionadas aos gêneros do discurso, em dois momentos: (1) no manual do professor e (2) no livro do aluno, ao longo das atividades de leitura e produção textual. A seleção dos dados obedeceu a critérios de dominância, procurando traduzir posturas que se revelam na organização geral e apresentação das atividades ao longo das obras analisadas. Para alcançar tal objetivo, reflete-se, primeiramente, sobre o papel do livro didático no universo do brasileiro; em um segundo momento, são revisitadas as noções de texto, enunciado e gênero, conforme sugeridas por Bakhtin, para discutir a abordagem do texto como objeto de ensino; a quarta e quinta seções são destinadas, respectivamente, à discussão da abordagem teórico-metodológica adotada pelos dois livros, considerando os gêneros do discurso no manual do professor e nas atividades de leitura e produção textual. Por fim, ao longo das considerações finais, procura-se mostrar como a abordagem do gênero, nesses três espaços (manual do professor, atividades de leitura, atividades de produção textual), entrelaça-se, ou não, ao longo das obras. 


\section{A PRESENÇA DO LIVRO DIDÁTICO NO UNIVERSO DO BRASILEIRO}

No cerne das questões que envolvem o processo de ensino/aprendizagem formal de qualquer língua materna, estão as questões relacionadas à leitura e à escrita nessa mesma língua. Smith (1999, p. 12) aponta que constituem dois requisitos básicos para aprender a ler: "(1) a disponibilidade de material interessante que faça sentido para o aluno e (2) a orientação de um leitor mais experiente e compreensivo como um guia.”. Assinala, ainda, que não vivemos um momento de escassez, mas sim de excesso de materiais. Há uma grande oferta de suportes de leitura que vão do livro impresso à tela do computador. Igualmente, temos contato diariamente com uma infinidade de gêneros que circulam socialmente; ou seja, há muito texto, mas que textos são significativos para o processo de ensino/aprendizagem? Para o professor, guia nesse processo, persiste o dilema: que materiais são válidos para uso em contexto de sala de aula? Que textos podem ou devem ser explorados? Que gêneros são mais significativos para exploração em cada contexto de ensino/aprendizagem?

Se, por um lado, percebe-se que “[...] o livro didático não deve ser o único material a ser utilizado [em contexto de sala de aula], pois a variedade de fontes de informação é que contribuirá para o aluno ter uma visão ampla do conhecimento.” (BRASIL, 1998, p.96), por outro, reconhece-se que o Brasil é um país de dimensões continentais, assinalado por desigualdades sociais que se refletem fora e dentro da escola e onde a tradição de uso do livro didático é muito acentuada. Serra (2003) aponta que, segundo as informações trazidas pelo INAF $^{1}$ 2001, o livro didático era um dos suportes de leitura mais presentes nos domicílios brasileiros (há livros didáticos em 59\% das residências brasileiras), apenas atrás da Bíblia ou livros sagrados, dos dicionários (intensivamente distribuídos pelo MEC durante o governo do presidente Fernando Henrique Cardoso) e dos livros de receitas. Segundo dados fornecidos pelo INAF 2005 (INSTITUTO PAULO MONTENEGRO, 2005), ou seja, após quase dez anos da universalização da distribuição dos livros didáticos aos alunos do ensino fundamental (iniciada em 1997), os livros escolares estão presentes em $84 \%$ das residências brasileiras; apenas a presença da Bíblia e de livros sagrados ou religiosos é mais freqüente (89\%). Ainda é digno de nota, que a quantidade de livros presentes em cada domicílio é muito pequena, um terço das famílias entrevistadas registrou possuírem menos de dez livros e 45\% estimaram possuir entre onze e cinqüenta livros. Aliada, portanto, à tradição do uso do livro didático na sala de aula, há uma questão social, verificada no pouco acesso que muitas famílias têm a outros suportes de leitura.

A distribuição de livros didáticos de Língua Portuguesa para o ensino médio, sempre na modalidade volume único, iniciou-se em 2004, atendendo, nesse ano, a alunos do primeiro ano do ensino médio de escolas públicas situadas nas regiões Norte e Nordeste. A partir de 2005, essa distribuição estendeu-se às outras regiões brasileiras. Para o triênio 2008, 2009 e 2010, a avaliação realizada pelo MEC recomendou um total de onze títulos para a disciplina de Língua Portuguesa e estima-se que serão beneficiados um total de 7.141.943 alunos em 15273 escolas.

\footnotetext{
1 INAF - Indicador Nacional de Analfabetismo Funcional. Pesquisa realizada pelo Instituto Paulo Montenegro, criado pelo IBOPE, em uma amostra nacional de 2002 pessoas entre 15 e 62 anos, com o objetivo de levantar dados sobre o letramento de jovens e adultos. Segundo dados do próprio INAF, o intervalo de confiança da pesquisa é de 95\% e a margem de erro máxima é de 2,2 pontos.
} 


\section{GÊNEROS DO DISCURSO, TIPOS DE TEXTOS E SEQÜÊNCIAS TEXTUAIS: aproximações e distanciamentos}

A modificação nas concepções que alicerçam o ensino médio no Brasil, preconizada pela Lei Darcy Ribeiro e concretizada nos Parâmetros Curriculares Nacionais para o Ensino Médio (PCNEM), levou à definição de uma nova organização curricular que desse prioridade à aquisição de competências mais gerais, as quais contribuíssem para inserção e ressignificação da realidade sociocultural em que o estudante se insere, em lugar de priorizar um currículo enciclopédico. Busca-se “[...] trabalhar as linguagens não apenas como forma de expressão e comunicação, mas como constituidoras de significados, conhecimentos e valores [...]” (BRASIL, 2000, p.74) que permeiam a sociedade, privilegiando estratégias de ensino que mobilizem mais o raciocínio e as competências cognitivas superiores, do que a memorização de conteúdos, os quais, freqüentemente, não fazem sentido para o estudante.

Esse redimensionamento de diretrizes e objetivos para a educação, experienciado no ensino médio, levou, naturalmente, à redefinição dos pressupostos teóricometodológicos que dão suporte ao ensino/aprendizagem da Língua Portuguesa. Assim, acolheu-se o texto, visto como elemento mediador da comunicação em suas diversas nuances, como objeto de ensino.

Isso envolve vê-lo enquanto “[...] enunciado na comunicação verbal (cadeia de textos) de uma dada esfera.” (BAKHTIN, 1997b [1959/61], p. 331), portanto, vinculado aos jáditos socialmente compartilhados e aos enunciados pré-figurados que comportarão ecos de significados por ele (texto) veiculados. Se, por um lado, o texto vincula-se ao sistema da língua, por outro, enquanto enunciado, ele se revela "individual, único e irreproduzível” (BAKHTIN, 1997b [1959/61], p. 331). As diferentes esferas de utilização da língua, entretanto, a partir da articulação de três elementos: conteúdo temático, estilo e construção composicional, elaboram "tipos relativamente estáveis de enunciados" a que Bakhtin denomina "gêneros do discurso" (BAKHTIN, 1997a [1952/53]). Os diversos gêneros, orais e escritos, vinculam-se a uma enorme variedade de funções que permeiam as várias esferas da atividade humana. O gênero tanto baliza o locutor na produção do enunciado, quanto orienta o ouvinte/leitor na produção de significados.

Outrossim, todo texto, assim como todo signo ideológico, surge assinalado pelo "[...] horizonte social de uma época e de um grupo social determinados.” (VOLOCHINOV, 2004, p. 44, grifo do autor) e o embate entre os diversos índices de valor dão vida e mobilidade ao signo, o que justifica a própria natureza flexível e mutável da língua, enquanto sistema de signos lingüísticos. Uma vez que o indivíduo se utiliza de sua língua materna para atender às suas necessidades comunicativas e que "[...] o centro de gravidade da língua não reside na conformidade à norma da forma utilizada, mas na nova significação que essa forma adquire no contexto.” (VOLOCHINOV, 2004, p. 92), cabe à escola romper com uma tradição secular de estudo centrado na teoria gramatical, para abrir espaço para o estudo do texto sob uma perspectiva epilingüística (GERALDI, 2002). Isso implica a prática de produção textual e a prática de compreensão oral e em leitura, permeadas pela prática de análise lingüística, que, por sua vez, relaciona-se com todo um arsenal de atividades que possam proporcionar uma reflexão sobre a(s) linguagem(ns) em uso. 
Tomando como base o texto, as atividades relacionadas ao estudo da gramática são redimensionadas; estudar a gramática da língua portuguesa deixa de ter um objetivo notacional, para adquirir um objetivo interacional. Implica, portanto, refletir sobre as especificidades das modalidades oral e escrita, sobre a questão da adequação, sobre os diversos graus de formalidade, sobre a questão da variação e sobre o aprofundamento dos conhecimentos morfológicos, sintáticos e semânticos inseridos nos diversos contextos significativos.

No que diz respeito à questão do gênero, as Orientações Curriculares Complementares aos PCN (BRASIL, 2002, p. 62) ressaltam a importância da caracterização do gênero e de seus mecanismos de articulação, bem como, da percepção das seqüências e tipos no interior dos gêneros para que se propicie a "[...] leitura plena e produção de todos os significados [...]”.

A respeito das distinções entre a noção de tipo de texto e seqüência textual, vale observar as reflexões apresentadas por Bonini (2005) e Furlanetto (2002). Bonini (2005) aponta que Jean-Michel Adam propõe agrupar os gêneros do discurso a partir dos traços que compartilham em relação às seqüências textuais. Dessa forma, o conto e a notícia pertenceriam a uma mesma categoria de gêneros, a dos gêneros narrativos, uma vez que ambos são marcados pela presença dominante de seqüências narrativas. O conceito de seqüencia textual, por sua vez, deriva dos conceitos de base $e^{2}$ e tipo de texto e de superestrutura ${ }^{3}$ textual. Werlich (apud BONINI, 2005) aponta cinco tipos de texto: descrição, narração, exposição, argumentação e instrução; os quais se originam da interação: contexto (referência textual) - mente (processos cognitivos que se vinculam ao contexto e à produção do texto).

Já Koch e Fávero (1987), ao falar sobre tipos de texto, sugerem uma categorização diversa daquela defendida por Werlich e Jean-Michel Adam, com base em três critérios: (1) dimensão pragmática (macroatos de fala); (2) dimensão esquemática global (modelos cognitivos adquiridos culturalmente); e (3) dimensão lingüística de superfície (marcas de natureza sintático-semântica que influenciam a compreensão). À luz de tais critérios, apontam seis tipos textuais: narrativo, descritivo, expositivo ou explicativo, argumentativo stricto sensu, injuntivo ou diretivo e preditivo. Tanto as observações feitas por Koch e Fávero (1987), quanto as propostas por Dolz e Schneuwly (2004), parecem estar mais claramente vinculadas às seqüências textuais do que a tipos de texto, uma vez que "[...] qualquer tipificação só pode ser feita em termos de dominância, já que dificilmente se apresentam tipos textuais puros.” (KOCH E FÁVERO, 1987, p. 09), ou seja, atravessados por apenas uma seqüência textual; de fato, os textos são, na maior parte das vezes, compostos pela articulação de diferentes seqüências. Esse critério, a dominância de uma determinada seqüência textual, parece, assim, de certa forma, um critério vago e impreciso para categorizar os diferentes textos. Não só, por vezes, é difícil perceber que seqüência é dominante, como também, seria preciso definir se essa dominância se daria a partir de parâmetros quantitativos ou qualitativos.

\footnotetext{
${ }^{2}$ É definida em Bonini (2005, p.210) como “[...] uma unidade temático-formal, a partir da qual o texto tem início e se expande em direção a um dos cinco tipos [...]".

${ }^{3}$ Bonini (2005, p. 211) aponta que Adam adota a definição de van Dijk para superestrutura textual, entendendo-a como um "[...] esquema textual superposto às estruturas gramaticais.”.
} 


\section{A ABORDAGEM DO GÊNERO NO MANUAL DO PROFESSOR}

Ambos os livros aqui analisados, obedecendo a uma determinação do próprio MEC, constituem volumes únicos, destinados aos três anos do ensino médio, e compreendem a totalidade dos conteúdos relativos à disciplina de Língua Portuguesa e Literatura Brasileira.

O livro de Carlos Alberto Faraco, Português: Língua e Cultura (LD 1), é composto por 35 capítulos e dois apêndices (um abordando pontuação e outro abordando acentuação). Os capítulos se organizam em cinco diferentes blocos: Bloco de Textos (dezessete capítulos); Enciclopédia da Linguagem (cinco capítulos); Almanaque Gramatical (quatro capítulos); Guia Normativo (dois capítulos) e História da Literatura (sete capítulos). Independentemente da divisão em blocos, o autor aponta que o objeto de todos os capítulos é o texto. Os textos que figuram no livro provêm "de diferentes práticas sociais (da literatura, do jornalismo, da música popular, da publicidade).” (FARACO, 2003, p. 4)

O autor anota que foram escolhidos os gêneros discursivos que pareceram mais relevantes para a formação dos cidadãos e cidadãs, dando ênfase especial aos textos literários, pois esses "[...] têm maior permanência no tempo, organizam esteticamente grandes questões humanas e a própria linguagem verbal [...]” (FARACO, 2003, p. 4). Nota-se, entretanto, também, a presença acentuada dos textos da esfera jornalística. A seleção de textos compreende, segundo o autor: textos literários (crônicas, contos, romances e poemas); textos informativos (notícias, reportagens, enciclopédias); textos de opinião (entrevistas, editoriais, artigos) e textos publicitários.

O livro do professor distingue-se do livro do aluno pela presença do manual do professor, o qual constitui as primeiras 32 páginas do livro. Nesse manual, o autor apresenta de forma sucinta os princípios teórico-metodológicos que serviram de suporte à elaboração da obra; traça considerações a respeito do uso do livro didático no contexto da sala de aula; realiza uma reflexão sobre avaliação e sobre a abordagem sugerida pelo livro para questões relativas a leitura, produção textual e ensino da gramática normativa. Não há respostas dos exercícios, nem sugestões mais detalhadas para orientação do trabalho do professor, o que é apontado pelo Catálogo do Programa Nacional do Livro do Ensino Médio (BRASIL, 2000), como um possível problema para o professor pouco acostumado às propostas inovadoras sugeridas pela obra.

Segundo o catálogo do PNLEM (2004), o livro

[...] apresenta uma proposta teórico-meodológica inovadora, perceptível até na original divisão de seu conteúdo: o desenvolvimento das proficiências em leitura e produção de textos é o objetivo perseguido, ainda que, coerentemente com a opção pelo formato de compêndio, os capítulos se organizem em exposições teóricas. (BRASIL, 2004, p.53).

Apesar de não citar diretamente Bakhtin ou os trabalhos do Círculo ${ }^{4}$, nem mesmo entre as obras de referência para a formação continuada do professor, e de evitar, de certa

\footnotetext{
${ }^{4}$ Círculo de Bakhtin
} 
forma, o uso da expressão gênero do discurso, comportamento que só adota uma vez ao longo de todo o manual do professor, fica clara a referência aos conceitos esposados por ele (Bakhtin). No que se refere à concepção de língua, por exemplo, Faraco (2003, p. 8, grifo meu) aponta que essa constitui um "conjunto aberto e múltiplo de práticas sociointeracionais, orais ou escritas, desenvolvidas por indivíduos historicamente situados”, existente somente e efetivamente no contexto das relações sociais como "elemento constitutivo dessas múltiplas relações e nelas se constitui continuamente.”; o que coaduna com a visão de língua defendida por Volochinov (2004, p. 124) “A língua vive e evolui [sendo, portanto, um conjunto aberto e múltiplo] historicamente na comunicação verbal [ou seja, em práticas sociointeracionais orais e escritas]”.

Faraco parece referir-se aos gêneros do discurso, apesar de preferir o termo "tipos de texto”, quando fala da vinculação entre esses e as diferentes práticas sociais nas quais têm origem, realçando, igualmente, a postura responsiva do aluno frente ao texto: "Ler pressupõe, em primeiro lugar, familiarizar-se com diferentes tipos de textos oriundos das mais variadas práticas sociais. [...] perder a ingenuidade diante do texto dos outros, [...] implica reagir ao texto, dar-lhe uma resposta, [...]” (FARACO, 2003, p.6). Dessa forma, realça a idéia de texto enquanto enunciado e, portanto, elo na cadeia da comunicação verbal. Ainda assinala o papel do aluno como interlocutor apto a relacionar os já-ditos, que fazem parte de seu pré-construído, com os novos ditos que o texto lhe oferece, para, a partir daí, reagir ao texto, gerando novos enunciados com base em seu horizonte apreciativo. Tal possibilidade está vinculada ao fato de o autor perceber que o ato de ensinar LP está atrelado à necessidade de "[...] oferecer aos/às alunos/as a oportunidade de amadurecer e ampliar o domínio que eles/elas têm das práticas de linguagem [...]” (FARACO, 2003, p.2).

O livro de William Roberto Cereja e Thereza Cochar Magalhães, Português: linguagens (LD 2), divide-se em nove unidades, com seis capítulos reunidos em três grupos: Literatura, Língua: uso e reflexão e produção de texto. Ao final de cada unidade, há uma seção denominada: Intervalo, a qual se divide em duas partes - imagem em foco e projeto.

O livro do professor traz respostas para os exercícios e apresenta, ao seu final, uma seção denominada manual do professor, constituído de 44 páginas, ao longo das quais os autores discorrem sobre os fundamentos teórico-metodológicos da obra, sua estrutura e apresentam sugestões de estratégias para o trabalho com as diversas unidades.

No manual do professor em LD 2 encontramos (CEREJA e MAGALHÃES, 2003, p.16):

Segundo Bakhtin, todos os textos que produzimos, orais ou escritos, apresentam um conjunto de características relativamente estáveis, tenhamos ou não consciência delas. Essas características configuram diferentes tipos ou gêneros textuais, que podem ser identificados por três aspectos básicos coexistentes: o assunto, a estrutura e o estilo (procedimentos recorrentes da linguagem).

Como se pode perceber, apesar de os autores mencionarem Bakhtin, utilizam a nomenclatura tipo ou gênero textual, os quais são tomados como termos sinônimos, apesar de corresponderem, como já mencionado anteriormente, a conceitos diferentes. 
Nota-se, assim, uma confusão teórica, reforçada ao se comparar os aspectos relacionados por Cereja e Magalhães ao conceito de gênero, a saber, assunto, estrutura e estilo; e aqueles sugeridos por Bakhtin, conteúdo temático, construção composicional e estilo.

Conforme esclarece Bakhtin (1997b [1959/61], p. 284), a construção composicional equivale a um “[...] tipo de estruturação e de conclusão de um todo, tipo de relação entre o locutor e os outros parceiros da comunicação verbal (relação com o ouvinte, ou com o leitor, com o interlocutor, com o discurso do outro etc.)", portanto constitui uma simplificação entendê-la como estrutura. Semelhantemente, a noção de conteúdo temático é mais ampla do que assunto.

Também em LD 2 (CEREJA e MAGALHÃES, 2003, p. 16), ao falar sobre a escolha do gênero, os autores ressaltam que

\begin{abstract}
A escolha do gênero não é completamente espontânea, pois leva em conta um conjunto de parâmetros essenciais, com quem está falando, para quem está falando, com que finalidade e qual é o assunto do texto. Por exemplo, ao desejarmos contar como ocorreu um conjunto de fatos, reais ou fictícios, fazemos uso de um texto narrativo, para instruirmos alguém sobre como fazer alguma coisa [...] fazemos uso de um texto instrucional [...].
\end{abstract}

Apesar de, em um primeiro momento, referirem-se ao fato de a escolha do gênero ser balizada pelo "querer-dizer do locutor", "intuito discursivo" e pelos parceiros da comunicação verbal; em um segundo momento, evidencia-se que os gêneros do discurso são tomados por tipos ou seqüencias textuais, quando se sugere que o texto narrativo e o texto instrucional constituem gêneros. Percebe-se, assim, confusão semelhante àquela enunciada no texto dos documentos oficiais.

De fato, os conceitos mobilizados pelo texto apontam mais na direção da apreensão da noção de gênero conforme sugerida pelo grupo de Genebra, do que conforme apresentada por Bakhtin; logo, condizente com a proposição de Schneuwly e Dolz (2004). Esses autores propõem agrupar os gêneros com base em critérios relativos ao domínio social da comunicação, capacidades da linguagem envolvidas e tipologias já existentes, definindo-se, assim, os gêneros do agrupamento do narrar, do relatar, do argumentar, do expor e do descrever ações.

Essas observações são ratificadas por Cereja e Magalhães (2003, p.17), que citam os trabalhos do grupo de Genebra, principalmente, no que tange à compreensão do gênero como ferramenta, "[...] um instrumento com o qual é possível exercer uma ação lingüística sobre a realidade.” e a serviço da construção do sujeito, pois “[...] o domínio dos diferentes tipos de gêneros textuais, por parte do aluno, não apenas o prepara para eventuais práticas lingüísticas, mas também amplia sua compreensão da realidade, apontando-lhe formas concretas de participação social como cidadão”. Para tanto, os autores propõem um esquema de aprendizagem em espiral e criticam a abordagem metodológica convencional de privilegiar o ensino da narração e da descrição nas séries iniciais, em detrimento de textos ditos dissertativos; porém mantêm o paradigma encenado pela leitura e produção de textos denominados narrativos, descritivos e dissertativos. 


\section{OS GÊNEROS DO DISCURSO EM ATIVIDADES DE LEITURA E PRODUÇÃO TEXTUAL}

Ao longo deste capítulo, interessa-nos analisar o modo de abordagem dos gêneros do discurso no âmbito dos dois livros aqui analisados (Português: Língua e Cultura e Português: Linguagens) no que tange às atividades de leitura/prática de compreensão oral e produção textual tanto de textos escritos quanto de textos orais.

\subsection{A abordagem metodológica em Português: Língua e Cultura (LD 1)}

No que tange ao LD 1, o catálogo do PNLEM (BRASIL, 2004, p. 55) aponta que a separação entre práticas de leitura e produção de textos é quase imperceptível, e a proposta de ensino de leitura "[...] tem um caráter progressivo e prevê o trabalho com textos de diversas esferas de uso, o que favorece a formação de um leitor crítico e proficiente em diversas situações sociais de uso da leitura.”.

Efetivamente, as atividades relacionadas à prática de leitura e escrita concentram-se nos capítulos do bloco de texto ${ }^{5}$. Tais capítulos iniciam com a apresentação de diferentes textos do gênero, cada qual seguido por uma seção denominada Estudo do Texto. Normalmente, há uma seção destinada a apresentar comentários mais aprofundados sobre o gênero e, ao final do capítulo, procurando recuperar o conteúdo construído, há a sugestão de uma ou mais práticas de produção textual.

O primeiro e o segundo capítulos são destinados ao estudo da crônica como gênero e recebem o nome de "Histórias que a vida conta (1) e (2)". O autor introduz o primeiro capítulo, realçando a relação entre os textos que produzimos oralmente, ao contarmos histórias do dia-a-dia, e o universo da escrita, principalmente da crônica, do conto, do romance, dos filmes, da história em quadrinhos, das peças de teatro e da novela de televisão. Em seguida, aponta: "Se contar histórias (reais ou inventadas) é uma atividade que todos sabemos fazer bem na fala, podemos, então, aproveitar essa nossa habilidade como ponto de partida para aprimorar nossa prática escrita.” (FARACO, 2003, p.8). Ao traçar tais comentários, o autor enfatiza o vínculo entre a escrita e a fala e aponta na direção de que o nosso enunciado é permeado por outros muitos enunciados que o precederam. Em seguida, sugere que, antes de escrever, o aluno leia algumas crônicas. A primeira crônica apresentada é Mar de Rubem Braga. Em seqüência, na seção “Comentários sobre a crônica”, Faraco aponta:

O texto que acabamos de ler é - como dissemos - uma crônica. Vamos aproveitar para dar destaque a algumas das características deste tipo de texto.

O assunto da crônica é, em geral, um fato vivenciado pelo seu autor. Um desses inúmeros acontecimentos que povoam nossa vida de todo dia. Acontecimentos que ficam muito fortes na nossa memória (como no texto de Rubem Braga), mas também episódios que chamam a atenção pelo seu lado pitoresco ou engraçado. Ou, ainda, situações inesperadas ou absolutamente banais, mas que - como se diz - nos fazem pensar na vida.

\footnotetext{
${ }^{5}$ Referimo-nos aos dezessete capítulos nomeados, em Faraco (2003), Bloco de Textos.
} 
Por isso é que a crônica tem um certo aspecto jornalístico: é como se o autor estivesse nos dando uma notícia do evento que ele vivenciou. Contudo, diferente da notícia, a crônica não é um relato frio (distante, objetivo) do evento: o autor faz questão de deixar bem claro que a perspectiva com que está apresentando o evento é bem particular, bem pessoal, bem subjetiva.

Daí também o tom de informalidade da crônica; esse ar de "conversa entre amigos", de "veja só o que me aconteceu”- que a caracteriza. Por tudo isso, a crônica é um tipo de texto muito adequado para relatarmos as muitas "histórias que a vida conta"; para explorarmos o humor do cotidiano; para deixar aparecer o lado lírico, mas também o lado trágico do nosso dia-a-dia.

Um detalhe interessante - nesse último caso, a crônica, pelas características que acabamos de ver, é o tipo de texto que facilita ao autor abordar de uma maneira mais leve um tema penoso, difícil, doloroso, quebrando o tom sério com que o trágico costuma ser tratado. Uma última característica: na crônica o autor não faz apenas o relato de um evento; ele, em geral, aproveita esse evento como pretexto para pensar um pouco na vida, para fazer uma reflexão breve, para tirar uma lição daquilo que vivenciou. No texto que lemos, Rubem Braga, além de relatar o evento ("A primeira vez que eu vi o mar”), faz também algumas reflexões motivadas pela lembrança daquele dia tão marcante ("Este homem esqueceu, grande mar, muita coisa que aprendeu contigo...”). (FARACO, 2003, p.11, grifo do autor).

Como se pode perceber, inicialmente, ao longo dos dois primeiros parágrafos, há referências à dimensão temática do gênero. Em seguida, o autor refere-se à esfera à qual a crônica se vincula (esfera jornalística), traçando um comparativo entre a crônica e a notícia; ao fazê-lo, ressalta a objetividade da segunda, em comparação à subjetividade da primeira. Observam-se, também, referências à dimensão estilística do gênero, que, como mencionado pelo autor, é suscetível às marcas de seu estilo individual. Em seguida, entretanto, ao falar sobre o tom de informalidade do gênero, ressalta que "[...] a crônica é um tipo de texto muito adequado para [...] explorarmos o humor do cotidiano; para deixar aparecer o lado trágico do nosso dia-a-dia.” e que “[...] é o tipo de texto que facilita ao autor abordar de uma maneira mais leve um tema penoso, difícil, doloroso, quebrando o tom sério com que o trágico costuma ser tratado.”. Em ambos os trechos, o autor opta por qualificar o gênero como tipo de texto apesar da distinção teórica já apontada entre ambos os conceitos. Nota-se, ainda, que a crônica é vista sob uma perspectiva reducionista, sinalizando apenas o uso de recursos relacionados ao humor para relatar, ou parodiar, a vida real. Deixa-se de anotar, portanto, recursos outros, tais como, a ironia e o sarcasmo etc. Igualmente, menciona-se uma das intenções discursivas que pode ser mobilizada pelo autor, a de provocar uma reflexão a respeito de um assunto específico. Da maneira como é enunciado pelo autor, todavia, sugere uma generalização, como se somente essa intenção discursiva pudesse se ver refletida no gênero, o que constituiria imprecisão.

A interlocução também fica na sombra; de fato, não há referências ao universo do cronista, a seu papel social, nem ao leitor previsto. De forma semelhante, apesar de o suporte de leitura onde o texto foi originalmente publicado ser mencionado, não há uma preocupação em explorar-se o espaço de ancoragem do texto neste suporte, assim não 
são feitas diferenças entre crônicas publicadas em livro, jornal impresso ou revista, o que assinala uma homogeneização da abordagem teórico-metodológica do gênero que enfraquece a sua vinculação fundamental a uma determinada prática social.

Ainda no primeiro capítulo, é sugerida a leitura de outras quatro crônicas: Professores de inglês (Cecília Meireles), No aeroporto (Carlos Drummond de Andrade), Pequenas aprendizagens (Jamil Snege) e Natal (Luís Fernando Veríssimo). Em relação a tais crônicas, realça-se o caráter humorístico, lírico e trágico, porém, só na última, destinada à leitura lúdica, fala-se na ironia e no aproveitamento estilístico da linguagem coloquial. Caberia ao professor traçar um paralelo entre os diversos textos; as diferentes leituras de mundo que cada autor imprime em seu texto; as marcas estilísticas próprias do gênero e aquelas que são próprias do autor; os diferentes públicos (leitores previstos) que visam alcançar; os usos lingüísticos predominantes que permitem a emergência do humor, do lirismo, do trágico; os recursos agenciados para parodiar ou recriar a realidade.

O texto de Luís Fernando Veríssimo, dada a sua atualidade e a proximidade do universo do adolescente, mereceria ser mais explorado pelo autor, no entanto, aqui, parecem faltar sugestões de como essa crônica deveria ser abordada pelo professor. Caso esse texto seja relegado à leitura opcional por parte do aluno, supõe-se que se perderia uma fonte bastante relevante de informações e de reflexão sobre o gênero. Outrossim, percebe-se que o livro pressupõe um professor com conhecimento teórico-metodológico suficiente para elaborar estratégias que permitam o aprofundamento da abordagem teórico-metodológica sugerida pelo autor.

A seqüência dos gêneros apresentada no livro confirma uma abordagem que oscila entre a noção de gênero do discurso e de tipo ou seqüencia textual. Dessa forma, se os dois primeiros capítulos se centralizam no estudo da crônica e o quarto capítulo, por exemplo, destina-se ao estudo do conto, no quinto capítulo, aborda-se o texto narrativo; nos capítulos 14 e 15, os textos informativos; e, no capítulo 27, aborda-se a dissertação.

No que tange à produção textual, há, no final do capítulo, uma proposta não diretiva de escrever-se uma (ou várias) crônica(s) com base nos comentários traçados ao longo da análise dos textos do gênero utilizados nas atividades de leitura. A proposta, entretanto, carece de objetividade, pois não é fornecido ao aluno o contexto social de interação, o intuito discursivo, o papel social do autor e a figura do interlocutor. Menciona-se que os colegas irão desejar ler os textos uns dos outros, porém não é registrado que o texto deve ser produzido com esse fim. Também não são sugeridas atividades de reescrita do texto do aluno, nem é explicitado o processo de planejamento textual. Logo, a atividade de produção textual parece ficar mais a cargo da intuição do que da reflexão. Como se pode perceber no trecho a seguir, estima-se que, com base nas leituras realizadas, o aluno tenha sido capaz de construir um conhecimento tal sobre o gênero, que lhe sirva de base para a elaboração de seu(s) próprio(s) texto(s).

Vamos, então à nossa primeira prática e escrita! Propomos que você escreva uma crônica (ou várias). Quer dizer: relate por escrito uma (ou várias) dessas "histórias que a vida conta".

As possibilidades são, obviamente, inúmeras. Lembre-se de que nossa memória está povoada dessas histórias: um acontecimento na rua, uma 
evento inesquecível de suas infância, um episódio numa atividade esportiva, um encontro inesperado e assim por diante.

Qualquer dessas histórias pode facilmente se tornar um texto bem interessante. E isso vai ficar logo evidente: observe como uns vão querer ler os textos dos outros. (FARACO, 2003, p.17).

As atividades envolvendo gêneros multimodais são poucas, porém apresentam uma abordagem diferenciada, realçando o entrelaçamento de diversas linguagens. A atividade abaixo surge na esteira de uma reflexão sobre a linguagem da esfera publicitária, na qual é realçado o entrelaçamento de diversas linguagens: linguagem visual, linguagem musical, linguagem verbal. Quanto à linguagem verbal, evidencia-se o uso de sentenças curtas; argumentos simples, diretos e "indiscutíveis" (FARACO, 2003, p. 433, 434). Além disso, sublinha-se o conteúdo jocoso e polissêmico presente na propaganda, entretanto apenas uma das atividades propostas no capítulo destina-se efetivamente ao trabalho com os gêneros da esfera, as demais atividades tencionam levar o aluno a refletir sobre as armas que a esfera da propaganda mobiliza para conquistar consumidores e sobre a propaganda enganosa. De certa forma, parece que, erroneamente, o livro toma a propaganda impressa ou na TV como prototípica da esfera ou "mais relevante" dentro dessa mesma esfera.

1. Escolha, num jornal ou revista, uma ou mais publicidades e, em pequenos grupos, analise cada uma observando:

- a sua configuração gráfica (proporção e distribuição especial da imagem e texto escrito, cores, tamanho das letras etc.);

- as características da parte verbal (algum aspecto lingüístico chama a atenção em especial?)

- a relação imagem-produto (que valores sociais estão subjacentes nessa relação; que valores sociais são reiterados pela associação de imagem e produto?).

2. Aplique o mesmo roteiro na análise de publicidades veiculadas pela televisão.

3. Analise, agora, a publicidade a seguir. Seu objetivo era conquistar leitores para uma determinada revista semanal.

- Observe que ela se sustenta no contraste entre duas imagens sociais do jornalismo. Quais são essas imagens?

- Como se articulam figura e texto nesta publicidade?

- Que sentido tem, no contexto desta publicidade, o enunciado:

"Porque beleza o Brasil já tem de sobra. O que falta mesmo é transparência”? (FARACO, 2003, p. 434-435)

Observa-se que a atividade chama a atenção para a relação entre as diferentes materialidades semióticas no que tange à construção do sentido. Novamente, entretanto, os interlocutores parecem ficar na sombra. Não há, nem no roteiro sugerido por LD 1 para análise preliminar de propagandas retiradas de revistas e jornais, nem no roteiro sugerido para análise da propaganda específica, alusão ao público leitor da revista ou jornal, e, portanto, público-alvo da propaganda; nem ao anunciante. Tanto o suporte de leitura (jornal Folha de São Paulo), quanto o anunciante (revista IstoÉ), porém, podem ser identificados na atividade. Mais uma vez, caberia ao professor chamar a atenção para ambos e sugerir, possivelmente, a análise do perfil dos leitores da Folha de São 
Paulo e da própria revista IstoÉ para que os mecanismo sociodiscursivos do gênero fossem mais amplamente explorados.

No que se refere aos gêneros orais, o Catálogo dos Livros do Ensino Médio assinala que "a linguagem oral, em geral negligenciada pelo ensino tradicional, é abordada de forma correta e pertinente, privilegiando-se as situações de uso público e formal da oralidade.”(BRASIL, 2004, p.53); entretanto, em um segundo momento, ao se referir às propostas de produção de tais gêneros, aponta que elas estão invariavelmente vinculadas à apresentação de resultados de pesquisa (sem, no entanto, explicitar como seria feita), a leituras dramáticas e à discussão de trabalhos produzidos; o que pode realmente ser percebido em uma leitura atenta da obra. Apesar de tais atividades serem relevantes, parecem insuficientes para a abordagem de gêneros orais se comparadas à grande variedade desses gêneros que poderiam ser contemplados ao longo dos diversos capítulos do livro (música, jingle, entrevista etc.).

\subsection{A abordagem metodológica em Português: Linguagens (LD 2)}

Em LD 2, como sugerido no próprio manual do professor, os autores optam por uma abordagem mais centralizada na abordagem francófana do gênero, evidenciando-se, principalmente, as concepções defendidas pelo grupo de Genebra no que diz respeito a seqüências didáticas, progressão e agrupamentos de gêneros (DOLZ; SCHNEUWLY, 2004). Assim, as unidades abordam, por exemplo: o texto argumentativo oral e o texto argumentativo escrito, que correspondem ao grupo do argumentar; o relato, que corresponde ao grupo do relatar; e o texto dissertativo-argumentativo que talvez pudesse ser localizado na interface entre o argumentar e o expor. Ao invés de serem identificados como agrupamento de gêneros, segundo a perspectiva do grupo de Genebra, são, porém, tomados como gêneros discursivos.

Ao falar do texto dissertativo-argumentativo, fica clara sua vinculação ao agrupamento do expor e do argumentar, entretanto a dissertação é configurada como gênero do discurso em igualdade, por exemplo, com o relatório, como pode ser observado no trecho a seguir: "Dissertar é o mesmo que desenvolver ou explicar um assunto, discorrer sobre ele. Assim, o texto dissertativo pertence ao grupo dos textos expositivos, juntamente com o texto de apresentação científica, o relatório, o texto didático, o artigo enciclopédico.” (CEREJA e MAGALHÃES, 2003, p. 445). Ao lado desse comentário, há uma observação que nos faz pressupor o porquê da abordagem deste tipo textual: $a$ redação do vestibular. Em seguida, há uma proposta de leitura e análise de um texto configurado como dissertativo-argumentativo, ao longo da qual não há qualquer menção a suporte de leitura, época da publicação, leitor previsto, papel social do escritor no contexto de enunciação, o que compromete até mesmo a identificação do gênero, que poderia constituir um artigo assinado, o editorial de um jornal escolar, entre outros. Percebe-se que a análise centra-se em aspectos textuais de ordem estrutural, enfatizando sua divisão em tese, desenvolvimento e conclusão; mas também, abordando o predomínio do padrão culto; o caráter persuasivo; o uso do presente do indicativo; a objetividade. A seguir surge uma proposta de produção textual, atrelada à mesma perspectiva de abordagem teórico-metodológica do texto. 
Em outros momentos do livro, propõe-se a análise de esferas da atividade humana, que são caracterizadas como gênero. É o caso do teatro, parte da esfera da arte. O capítulo 5 destina-se à abordagem do texto teatral, entretanto, sob essa "classificação", poder-se-ia conceituar um número de gêneros diversos que iriam do monólogo ao auto. Para falar do gênero, os autores propõem a análise de um trecho da obra Auto da Compadecida de Ariano Suassuna. Em um primeiro momento da análise, anota-se a seguinte observação: "O texto teatral e o texto narrativo apresentam alguma semelhança: tanto um quanto o outro narram fatos vividos por personagens em determinado tempo e lugar." (CEREJA e MAGALHÃES, 2003, p. 67). Como se pode perceber, surge aqui uma confusão entre gênero e tipo textual (texto narrativo). Ainda mais uma vez, é a abordagem dos aspectos textuais, principalmente no que tange à estrutura do texto, que prevalece. Os autores anotam a freqüente inexistência de narrador, a presença dos elementos básicos da narração (fatos, personagens, tempo e lugar), a presença marcante do discurso direto, a divisão em atos, a identificação da personagem antes de sua fala, a apresentação de rubricas de interpretação e de movimento. Em nenhum momento, traçam-se considerações relativas aos interlocutores, nem mesmo ao universo do autor, seu papel social, sua intenção comunicativa, seu estilo. Menciona-se que o texto foi adaptado para a TV, porém não são discutidas possíveis adaptações, ou o espectador previsto, horário de exibição etc. De fato, percebe-se, claramente, uma generalização. Em nenhum momento dá-se atenção ao exemplar do gênero - o auto - mas, sim, aos aspectos estruturais dos textos que permeiam o teatro, entendido como uma parte da esfera da arte.

Coisa semelhante ocorre com o texto publicitário. A partir de dois anúncios publicitários impressos, é proposta uma atividade que visa a refletir não sobre o gênero, mas sobre os gêneros, de forma geral, circunscritos à esfera da propaganda, buscando uma generalização que deixa de lado a diferença entre cada um deles especificamente. De fato, a abordagem escolhida pelos autores é bastante homogeneizadora e reúne, sob as mesmas características, gêneros tão distintos quanto a propaganda em outdoor e a propaganda impressa em jornal, assinalando que "Os anúncios publicitários pertencem ao gênero argumentativo, pois sua finalidade central é persuadir o interlocutor." (CEREJA e MAGALHÃES, 2003, p. 356).

Em outros momentos, no entanto, trabalha-se o gênero, mesmo que numa perspectiva que valorize mais a textualidade, do que a discursividade. Isso ocorre principalmente com gêneros da esfera jornalística como a reportagem, a notícia e a crônica. No caso específico da reportagem, há, no capítulo 24, uma proposta de trabalho com os textos Acabou o vestibular e Uma avaliação negativa publicados na Revista Veja.

1.Os textos lidos discutem, com base em fatos e opiniões, o exame vestibular no Brasil. No $1^{\circ}$. Parágrafo do texto principal [Acabou o vestibular] encontra-se o lead, que responde às perguntas básicas de uma notícia: o quê, quem, quando, onde, como, por quê.
a) Qual é o fato?
b) Onde esse fato tem ocorrido?
c) Como isso tem sido feito?
d) Por que esse fato tem ocorrido? 
2. Os demais parágrafos do texto ampliam o lead, acrescentando novos fatos, questionando suas causas e efeitos e interpretando-os [...]

a) Qual é a razão de faculdades particulares de baixo nível abolirem o vestibular?

b) Quais as conseqüências positivas do fim do vestibular tradicional?

[...]

4. O reporte usa uma linguagem impessoal. Entretanto, em certas situações, deixa transparecer sua posição sobre o assunto tratado. Identifique no texto, marcas da opinião dele.

5. Você deve ter observado que outros fatos estabelecem conexões com o fato principal. Como esses fatos novos são narrados?

a) De forma impessoal, com simplicidade e objetividade.

b) De forma pessoal, ou seja, subordinada ao ponto de vista do repórter, que vai orientando a opinião do leitor.

c) Com o apoio de entrevistas concedidas por pessoas envolvidas na situação e na opinião que elas expressam.

d) Com o apoio de outros textos, que trazem informações e pontos de vista novos.

9. Observe a linguagem empregada no texto:

a) Que características ela apresenta? [...]

b) Que tipo de variedade lingüística é empregada: a padrão ou a não-padrão? (CEREJA e MAGALHÃES, 2003, p. 259-260).

Sugere-se, primeiramente, a interpretação do texto e, em seguida, há uma reflexão a respeito da linguagem utilizada, a variedade lingüística empregada e as relações dialógicas entre os textos e outros textos (já-ditos), ainda que em nenhum momento essa relação e o seu porquê sejam aventados no que diz respeito à intenção discursiva.

A relação entre o texto e as imagens que os ilustram também é alijada da discussão. Igualmente, não é feita qualquer menção aos interlocutores ou ao estilo (seja esse do gênero, da revista, ou do autor).

A atividade de produção de texto (reportagem) que é proposta na seqüência (em dupla), apresenta dez sugestões de assunto, e assinala:

Escolhido o assunto, sigam as instruções:

- Se necessário, busquem informações em jornais, revistas e livros.

- Façam entrevistas com pessoas que entendam do assunto, procurando obter várias versões e opiniões sobre o tema escolhido.

- Selecionem e organizem o material obtido.

- Escrevam a reportagem, considerando as características do gênero.

- Passem-na a limpo e, se possível, ilustrem-na com fotografias. Dêem-lhe um título que atraia a atenção do leitor e, ao mesmo tempo, anuncie o assunto. Coloquem um subtítulo, se julgarem necessário.

- Afixem a reportagem no mural da escola para que todos possam lêla. (CEREJA e MAGALHÃES, 2003, p. 261)

Percebe-se, assim, uma preocupação: (1) com a alimentação temática e a interlocução com outros enunciados, apesar da natureza das relações entre o texto e outros 
enunciados não ter sido mais profundamente explicitada na atividade de leitura; (2) com a obediência às características composicionais do texto apontadas em box situado na página anterior;(3) e com o espaço de circulação do texto: o mural da escola, que estabelece, como leitor padrão, a comunidade escolar.

No que tange a gêneros multimodais, LD 2 opta por uma abordagem que privilegia a propaganda impressa em revista (anúncio). Apesar de o livro ser pontuado pela sugestão de atividades diversas envolvendo outros gêneros multimodais, como, por exemplo, filmes e músicas, em nenhum momento há a preocupação de caracterizar tais filmes e músicas como gênero; na verdade, tais sugestões estão geralmente vinculadas a questões relativas ao ensino de literatura. Igualmente, os autores utilizam charges e diversas tiras de história em quadrinhos para a discussão e exemplificação de diferentes aspectos do uso da língua, sem, porém, vincular tais aspectos aos gêneros do discurso.

Por outro lado, o tratamento dado ao gênero propaganda impressa parece cobrir, em diferentes momentos, ainda que de forma fragmentada, tanto aspectos de ordem composicional, quanto aspectos estilísticos e de ordem temática. A interlocução entre as diferentes materialidades semióticas igualmente é realçada, principalmente no diálogo entre texto verbal e imagem. Muitas vezes, a leitura e a discussão da propaganda constituem uma atividade-meio e não uma atividade-fim ${ }^{6}$, ou seja, o texto publicitário não é discutido em si mesmo, mas é utilizado para discussão de fatores relacionados ao emprego ou não da norma padrão, da ambigüidade, da polifonia, entre outros.

Ao discutirem a polifonia, Cereja e Magalhães (2003, p.112) sugerem a seguinte atividade:

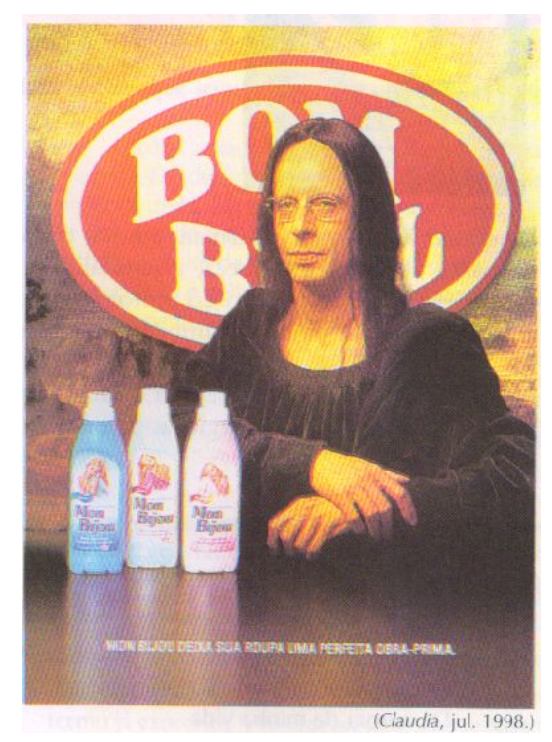

1.Que tipo de linguagem é utilizado na construção do texto: a verbal, a visual ou as linguagens verbal e visual?

2.Leia apenas a frase situada na parte inferior do anúncio [Mon Bijou deixa sua roupa uma perfeita obra-prima]. Qual é seu sentido?

\footnotetext{
${ }^{6}$ O conceito de atividade-meio é definido no Catálogo do Programa Nacional do Livro do Ensino Médio (2004, p. 61) como aquela atividade "que se presta como etapa preparatória para uma outra atividade.”.
} 
3.Observe a figura central do anúncio: a roupa, o cabelo, o meiosorriso da pessoa fotografada e o cenário ao fundo. Por esse conjunto de elementos, notamos que não se trata de um anúncio comum, pois há nele a voz de outro texto bastante conhecido. Que texto é esse?

4.Fazendo o cruzamento entre a parte verbal e a parte visual do texto, notamos que há entre as duas linguagens um ponto em comum, que as aproxima e amplia o sentido de cada uma. Qual é ele?

5.Ao lançar mão da polifonia discursiva como meio de promover seu produto, o anunciante pode correr alguns riscos, pois o leitor pode não conhecer a obra de Leonardo da Vinci.

a) Levando em conta que o produto anunciado é um amaciante de roupas (portanto algo refinado que nem todos utilizam) e que o anúncio foi publicado numa revista de público predominantemente feminino e de classe média, é provável que a maior parte dos leitores perceba a polifonia ou não? Por quê? [...]

6.Imagine como seria um anúncio tradicional desse produto (“Compre...”, “use...”, “experimente...”) e compare ao anúncio lido. Levante hipóteses: que vantagens há, para o anunciante, em criar um anúncio com esse tipo de inovação?

A atividade chama a atenção para articulação entre as linguagens visual e verbal, explorando os sentidos que podem ser ativados nessa relação; refere-se à interlocução entre o texto do anúncio e outros textos (a pintura Mona Lisa), assinalando a relação entre os enunciados e a reação-resposta do leitor previsto com base em seu préconstruído; fornece dados e discute o espaço de circulação da notícia, bem como caracteriza brevemente o perfil do leitor previsto; assinala a presença de uma regularidade discursiva do gênero no que se refere ao emprego de recursos lexicais; levanta uma reflexão sobre possíveis vantagens para o anunciante, decorrentes do estilo arrojado da propaganda.

Ao longo do capítulo 34, percebe-se uma preocupação por parte dos autores em sistematizar o conhecimento sobre o gênero, realçando o aspecto textual (estrutural), a vinculação entre a propaganda impressa (anúncio) e a argumentação, e sua construção composicional, sem, entretanto, elucidar sobre de que gênero do discurso se trata, como se percebe em:

Características do texto publicitário escrito:

- quase sempre constituído por imagem e texto;

- linguagem persuasiva, direta, clara;

- estrutura variável, mas geralmente composta por:

- título, que chama atenção sobre o produto;

- texto, que amplia o argumento do título;

- assinatura, logotipo ou marca do anunciante;

- nível de linguagem de acordo com o público que se pretende atingir;

- verbos geralmente no modo imperativo ou no presente do indicativo;

- uso de recursos como figuras de linguagem, ambigüidade, jogos de palavras, provérbios, etc. (CEREJA e MAGALHÃES, 2003, p. 357)

Por fim, no que se refere à abordagem de gêneros orais em LD 2, nota-se que, se por um lado, esses gêneros têm pouco espaço em atividades destinadas à leitura, no que se 
refere à produção textual, são oportunizadas situações de uso de gêneros orais nas seções nomeadas Intervalo, introduzidas ao final de cada unidade, ainda que a abordagem desses gêneros não seja sistematizada. Nessas seções, com o objetivo de abranger os diferentes conteúdos que constituem foco das discussões a respeito de Literatura Brasileira, é sugerida a realização de uma diversidade de atividades envolvendo a produção de: revista falada, revista cultural, júri simulado, programa de rádio. No caso do programa de rádio, por exemplo, dá-se maior ênfase à sugestão de diferentes assuntos que poderiam ser abordados; no que tange ao júri simulado, uma maior atenção é voltada às regras que coordenam a realização do júri e seus atores. Apesar de todas as atividades parecerem interessantes e motivadoras, constituindo excelentes sugestões de utilização da língua em sua modalidade oral, em todas as oportunidades os interlocutores são os colegas de turma e o professor, poucas observações são efetivamente traçadas sobre interlocutores reais, sobre o contexto social de interação, assim como sobre questões estilísticas.

\section{CONSIDERAÇÕES FINAIS}

A análise das obras didáticas que constituíram objeto desta pesquisa parece sugerir que a indefinição terminológica que cerca a questão do gênero acarreta imprecisões conceituais e influencia as bases teórico-metodológicas que dão suporte ao ensino de Língua Portuguesa.

A abordagem das questões relativas aos gêneros do discurso, nos manuais do professor, parece oscilar entre uma noção centrada na concepção bakhtiniana de gênero do discurso em LD 1, e, em LD 2, uma concepção de gênero que mescla as idéias do círculo de Bakhtin com as do grupo de Genebra, tendendo a uma abordagem que privilegia a textualidade em detrimento da interação, e a noção de tipo textual, em lugar de gênero do discurso. Outrossim, em diferentes momentos, principalmente em LD 2, percebe-se que se nomeia gênero o que é, na verdade, esfera da atividade humana, ou tipo textual.

Em ambos os livros, as atividades de produção textual são estimuladas a partir de práticas de leitura, entretanto, enquanto em LD 1 é sugerida leitura e análise de uma grande diversidade de textos, para que se possam apreender as características do gênero a ser trabalhado; em LD 2, as atividades de produção textual surgem na esteira de uma única atividade de leitura, a qual parece ser insuficiente para que o aluno construa uma noção mais ampla do gênero. No interior de tais atividades, tanto de leitura, quanto de produção textual, é sempre a dimensão composicional do gênero que recebe um tratamento mais apurado, sendo, por vezes, privilegiada, exclusivamente, a análise da organização textual.

No que se refere ao conteúdo temático, este parece ser muitas vezes entendido como "o assunto" em torno do qual o texto se organiza, desprezando-se sua finalidade discursiva e a sua orientação em função dos parceiros da interação verbal. De fato, tanto em LD 1, quanto em LD 2 (com exceção de algumas atividades referentes ao gênero propaganda impressa), os interlocutores parecem ficar à sombra da discussão. A dimensão estilística do gênero é poucas vezes explicitada e, quando o é, não é realçado o fato dos diferentes gêneros serem diversamente suscetíveis à impressão de marcas estilísticas do autor. Não 
é dada atenção ao fato de que, se, por um lado, alguns gêneros são bastante estáveis, outros, como a crônica (abordada ao longo dos dois primeiros capítulos de LD 1), constituem gêneros mais flexíveis. A discussão da dimensão estilística do gênero necessitaria, em LD 2, da presença de mais textos de um mesmo gênero para que o aluno pudesse efetivamente construir um conhecimento com base na comparação entre diferentes textos, o que lhe permitiria apreender que características se vinculam à estabilidade do gênero e quais estão atreladas ao estilo pessoal do autor. Em LD 1, a multiplicidade de textos oferecidos oportunizaria essa discussão, que, no entanto, não é realizada.

A abordagem dos gêneros multimodais, apesar de se circunscrever praticamente apenas à propaganda impressa, demonstra uma preocupação com a interação entre as diferentes materialidades semióticas e parece integrar, tanto o conteúdo temático, quanto a estrutura composicional, e o estilo do gênero, ainda que não de maneira explícita.

O tratamento de gêneros orais é pouco sistematizado e poucas são as atividades que visam a leitura e compreensão oral de textos de tais gêneros. Em LD 2, a leitura e a produção de textos orais preponderam ao longo das seções denominadas Intervalo. Na maior parte das vezes, entretanto, é dada ênfase à situação de interação e não ao gênero do discurso.

De forma geral, pode-se dizer que ambos os livros didáticos são assinalados pela tentativa de mudança de parâmetros de ensino/aprendizagem de língua portuguesa, constituindo obras de transição entre uma perspectiva imanente e uma perspectiva sócio-histórico-interacional de uso da língua; entre uma abordagem tradicional vinculada à noção de texto como estrutura, e uma visão renovada que entende o texto como enunciado, e, como tal, atrelado à noção de gênero do discurso.

\section{REFERÊNCIAS}

BAKHTIN, M. M. Os gêneros do discurso [1952/53]. In: Estética da criação verbal. São Paulo: Martins Fontes, 1997a. p. 277-324.

O problema do texto [1959/61]. In: Estética da criação verbal. São Paulo: Martins Fontes, 1997b. p. 325-358.

BASE. Ranking livro didático. Correio eletrônico. Curitiba, 2008.

BONINI, A. A noção de seqüência textual na análise pragmático-textual de Jean-Michel Adam. In: MEURER, J.L.; BONINI, A.; MOTTA-ROTH, D. (org.). Gêneros: teorias, metódos, debates. São Paulo: Parábola, 2005. p. 208-236.

BRASIL. Parâmetros Curriculares Nacionais: Introdução. Brasília: SEF, 1998.

Parâmetros Curriculares Nacionais Ensino Médio. Brasília: SEF, 2000. 
PCN Ensino Médio: orientações curriculares complementares aos Parâmetros Curriculares Nacionais. Linguagens, Códigos e suas Tecnologias. Brasília: SEF, 2002.

\author{
Catálogo do Programa Nacional do Livro do Ensino Médio - \\ PNLEM/2006: Língua Portuguesa. Brasília: SEF, 2004.
}

Orientações curriculares para o Ensino Médio - Linguagens, códigos e suas tecnologias. Brasília: SEF, 2006.

CerejA, W. R.; MAgalhãeS, T. C. Português: Linguagens. São Paulo: Atual, 2003.

SCHNEUWLY, B.; DOLZ, J. Gêneros e progressão em expressão oral e escrita elementos para reflexões sobre uma experiência suíça (francófona). In: ROJO, R.; FARACO, C. A. Português: língua e cultura.Curitiba: Base, 2003.

FURLANETTO, M. M. Produzindo textos: gêneros ou tipos? Perspectiva, Florianópolis, v. 20, n.01, p. 77-104, jan/jun. 2002.

GERALDI, J. W. Portos de passagem. 4. ed. São Paulo: Martins Fontes, 2002.

INSTITUTO PAULO MONTENEGRO, 5०. Indicador Nacional de Analfabetismo Funcional. São Paulo, 2005. Disponível em: http://www.acaoeducativa.org.br/ downloads/inaf05.pdf. Acesso em 04 de fev. de 2008.

KOCH, I. G. V.; FÁVERO, L. L. Contribuição a uma tipologia textual. Letras \& Letras. Uberlândia, vol. 03, n. 01, p. 03-10, março, 1987.

SERRA, E. D. Políticas de promoção da leitura. In: RIBEIRO V. M. (org.). Letramento no Brasil: reflexões a partir do INAF. São Paulo: Global, 2003.

SMITH, F. Leitura significativa. Trad. Beatriz Affonso Neves. Porto Alegre: Artmed, 1999. p. 01-66.

VOLOCHINOV, V. N. Marxismo e filosofia da linguagem: problemas fundamentais do método sociológico na ciência da linguagem. 11. ed. São Paulo: Hucitec, 2004. 